\title{
Advances in IoT and Smart Sensors for Remote Sensing and Agriculture Applications
}

\author{
Silvia Liberata Ullo ${ }^{1, *(1)}$ and G. R. Sinha ${ }^{2}(\mathbb{C}$ \\ 1 Engineering Department, Università degli Studi del Sannio, 82100 Benevento, Italy \\ 2 Department of Electronics and Communication Engineering, Myanmar Institute of Information \\ Technology (MIIT), Mandalay 05053, Myanmar; gr_sinha@miit.edu.mm \\ * Correspondence: ullo@unisannio.it
}

Citation: Ullo, S.L.; Sinha, G.R. Advances in IoT and Smart Sensors for Remote Sensing and Agriculture Applications. Remote Sens. 2021, 13, 2585. https://doi.org/10.3390/ rs13132585

Academic Editors: Manlio Bacco, Alberto Gotta, Pietro Cassarà and Johnson Ihyeh Agbinya

Received: 29 April 2021

Accepted: 28 June 2021

Published: 1 July 2021

Publisher's Note: MDPI stays neutral with regard to jurisdictional claims in published maps and institutional affiliations.

Copyright: (C) 2021 by the authors Licensee MDPI, Basel, Switzerland. This article is an open access article distributed under the terms and conditions of the Creative Commons Attribution (CC BY) license (https:// creativecommons.org/licenses/by/ $4.0 /)$.

\begin{abstract}
Modern sensors find their wide usage in a variety of applications such as robotics, navigation, automation, remote sensing, underwater imaging, etc. and in recent years the sensors with advanced techniques such as the artificial intelligence (AI) play a significant role in the field of remote sensing and smart agriculture. The AI enabled sensors work as smart sensors and additionally the advent of the Internet of Things (IoT) has resulted into very useful tools in the field of agriculture by making available different types of sensor-based equipment and devices. In this paper, we have focused on an extensive study of the advances in smart sensors and IoT, employed in remote sensing and agriculture applications such as the assessment of weather conditions and soil quality; the crop monitoring; the use of robots for harvesting and weeding; the employment of drones. The emphasis has been given to specific types of sensors and sensor technologies by presenting an extensive study, review, comparison and recommendation for advancements in IoT that would help researchers, agriculturists, remote sensing scientists and policy makers in their research and implementations.
\end{abstract}

Keywords: sensors; smart sensors; AI; IoT; remote sensing; agriculture applications

\section{Introduction}

Sensors are most commonly used in numerous applications ranging from bodyparameters' measurement to automated driving. Moreover, sensors play a key role in performing detection- and vision-related tasks in all the modern applications of science, engineering and technology where the computer vision is dominating [1-15]. An interesting emerging domain that employs the smart sensors is the Internet of Things (IoT) dealing with wireless networks and sensors distributed to sense data in real time and producing specific outcomes of interest through suitable processing [2,6,16-26]. In IoT-based devices, sensors and artificial intelligence (AI) are the most important elements which make these devices sensible and intelligent. In fact, due to the role of AI, the sensors act as smart sensors and find an efficient usage for a variety of applications, such as general environmental monitoring $[2,9,19,22,27-30]$; monitoring a certain number of environmental factors; weather forecasting $[15,21,29,31-33]$; satellite imaging $[21,27,34-38]$ and its use; remote sensing based applications [1,13,21,37,39]; hazard events' monitoring such as landslide detection [29]; self-driving cars; healthcare [4,6] and so on. In reference to this latter sector, recently the usage of smart devices has been hugely increased in hospitals and diagnostic centers for evaluating and monitoring various health conditions of affected patients, remotely as well as physically.

Practically, there is no field of science or research which performs smartly without using the modern sensors. The wide usage and need of sensors; and IoT employed in remote sensing, environment and human health monitoring make the applications as intelligent. In the last decade, the agriculture applications have also included the utilization of many types of sensors for monitoring and controlling various types of environmental parameters such as temperature, humidity, soil quality, pollution, air quality, 
water contamination, radiation, etc. This paper also aims to highlight the use of the sensors and IoT for remote sensing and agriculture applications in terms of extensive discussion and review.

First, the contribution in the area of IoT and sensors used for various applications related to environment, agriculture and remote sensing is highlighted in the Table 1, where methods used, contributions and limitations are presented for a selected number of papers. In [18], a critical review and recommendations are presented with the focus on various types of sensors and IoT devices, used for monitoring some parameters of the environment such as water quality, air quality, radiation, sound pollution, etc. The research study recommends some peculiar to-do-objectives for implementing viable environment monitoring systems smartly with the help of sensors, IoT and AI. Advances in modern sensors, their physics and implementation strategies have been discussed vividly in [8]. This can be used as a good manual for studying and choosing an appropriate sensor for a specific application. Different types of IoT, their designs, implementations, challenges, privacy issues are discussed in $[2,6,17,19,40,41]$. Putting these characteristics altogether becomes very important to understand the most suitable type of IoT that could be viable for an application meeting the usage requirements. Edge computing has been discussed and suggested in [5] as an important technique for developing effective IoT applications. The different types of sensor networks used in deploying the sensor and the IoT-based applications are discussed in [20-22,24,28,42-44]. Miniaturized pervasive sensors are discussed in [10] that highlights how sensors can be miniaturized for intelligent applications in many fields so that the portable usage can make their utilization more flexible. Here, sensors used for agriculture and remote sensing are also discussed. A comprehensive survey of IoT and their applications is presented in [6] by highlighting the suitable choice of IoT in the desired application of remote sensing.

Table 1. Research studies, theories and surveys on IoT and Sensors.

\begin{tabular}{|c|c|}
\hline Research/Survey Category & Method Used, Contributions and Limitations \\
\hline Smart Monitoring [18] & $\begin{array}{l}\text { IoT and sensors are discussed used in Environment Monitoring Systems for } \\
\text { assessment of quality of water, air and radiation. The work highlights critical } \\
\text { review and recommendations. }\end{array}$ \\
\hline Modern Sensors [8] & $\begin{array}{l}\text { Different types of sensors with their physics, implementation and } \\
\text { scopes are covered. } \\
\text { This is a research-based book which highlights advances in modern sensors used } \\
\text { for numerous applications including agriculture and remote sensing. }\end{array}$ \\
\hline Internet of Things $[2,6,19,45]$ & $\begin{array}{l}\text { Theory, principles, review and survey of various types of IoT are discussed. A } \\
\text { good combination of theory and practices on IoT including privacy issues is } \\
\text { presented. Implementation strategies and the challenges are discussed in detail. }\end{array}$ \\
\hline IoT and Edge Computing [5] & $\begin{array}{l}\text { Edge Computing is the main contribution for IoT application. Open source model } \\
\text { and framework of IoT are suggested. The emphasis is on general purpose } \\
\text { applications rather than only agriculture or related uses. }\end{array}$ \\
\hline Sensor Networks [20-22,24,28,30,42-44] & $\begin{array}{l}\text { Different types of wireless sensor networks are the focus of these papers. Sensor } \\
\text { networks used in the deployment of various types of IoT and sensors are } \\
\text { discussed with the potential of different networks for various applications. }\end{array}$ \\
\hline Pervasive Sensors [10] & $\begin{array}{l}\text { Miniaturized Pervasive Sensors are used for health monitoring. In the } \\
\text { development of smart cities, smart health monitoring systems, the sensors play the } \\
\text { most significant role and for this reason miniaturized pervasive sensors are } \\
\text { discussed in detail with emphasis on the scope of implementations. This could be } \\
\text { used for agriculture and remote sensing applications as well. }\end{array}$ \\
\hline IoT: Comprehensive Survey [6] & $\begin{array}{l}\text { A Comprehensive Survey of IoT and their applications are discussed. This paper } \\
\text { highlights various surveys on IoT and their applications which would help in } \\
\text { choosing appropriate smart sensors and IoT for specific uses in remote } \\
\text { sensing applications. }\end{array}$ \\
\hline
\end{tabular}


There are numerous types of sensors and their classification is based on the physics involved; fabrication processes; performance metrics, application, etc. The focus of the sensors in this paper is on smart sensors and IoT especially used in remote sensing and agricultural applications.

The paper is organized as follows: in the Section 2, Smart Sensors for Remote Sensing Applications are introduced, while IoT for Remote Sensing Applications is discussed in the Section 3. Smart Sensors and IoT for Agriculture Applications are jointly discussed in Section 4, by explaining how advanced technologies employed in modern agriculture can help in improving its management and outputs. Discussion is carried out in Section 5, and Conclusions end the contribution in Section 6.

\section{Smart Sensors for Remote Sensing Applications}

As discussed in the previous section, the remote sensing applications become interesting and powerful if the smart sensors are used for smart sensing and detection of real time data and their analysis. Figure 1 depicts an application scenario in which the active and passive sensors [46] are used in remote sensing applications, which can range from those including navigation, surveillance, communication $[3,5,16,21,26,39]$, forecasting [13], biological research, earth resource monitoring, up to atmospheric condition monitoring $[26,43,47]$, etc. Weather monitoring, navigation, communication, forecasting assistance are major application areas of remote sensing employing different types of sensors. The sensors used in such applications behave smartly due to artificial intelligence (AI) techniques embedded in the sensors, also based on IoT for the specific purposes.

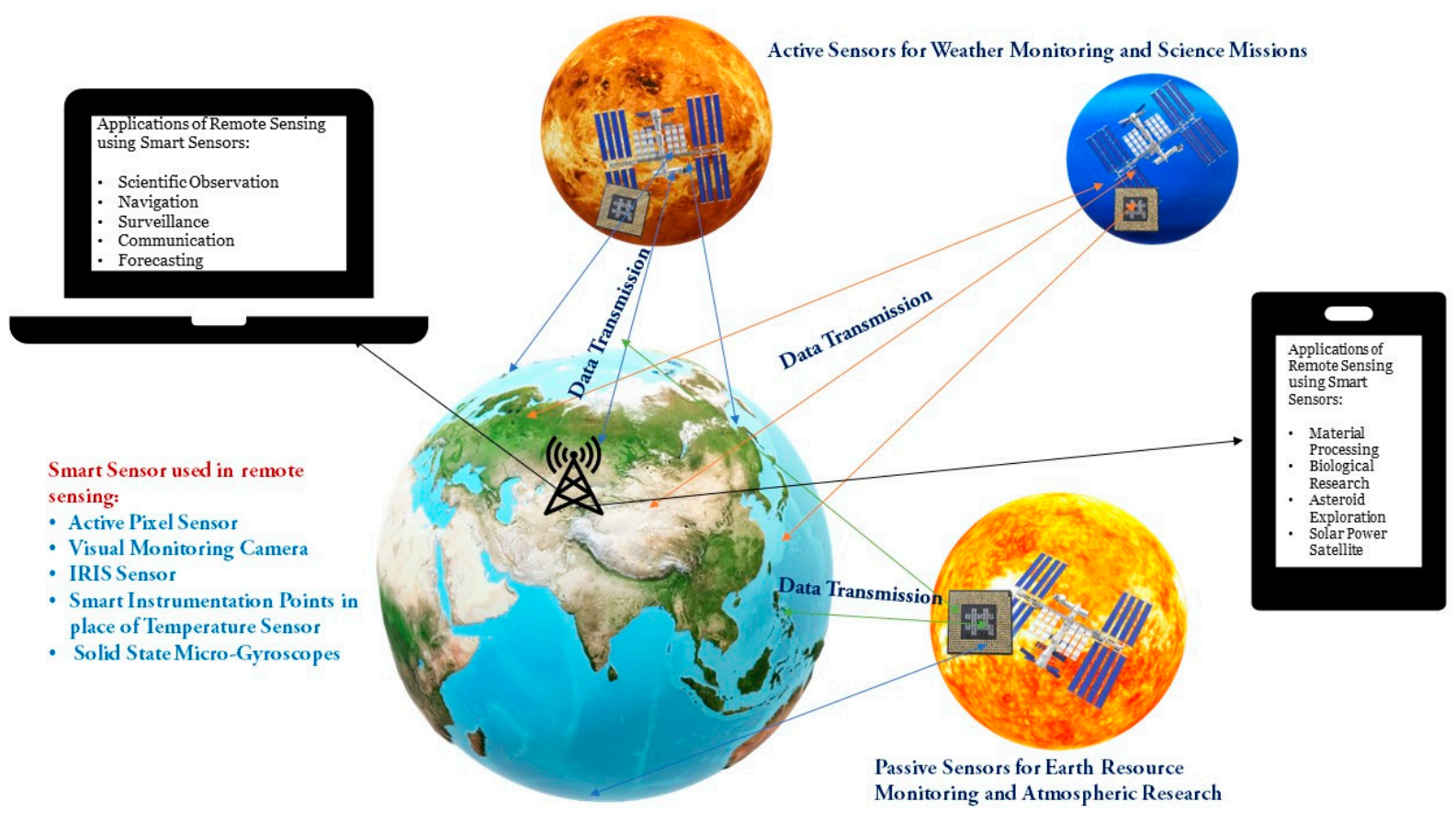

Figure 1. In [48,49], clarity of theory and concepts of different types of smart sensors are highlighted with explicit examples and their possible applications. Sensing impact is presented in [50] with focus on scope and impact analysis of various types of sensors used for industrial and other applications. Precision agriculture and satellite data processing are discussed in [35], which utilizes the remotely sensed LiDAR data and helps in smart agriculture applications.

Although, research papers on smart sensors for remote sensing applications are limited, few major research works with potential impact have been summarized in Table 2 . In $[48,49]$, clarity of theory and concepts of different types of smart sensors are highlighted with explicit examples and their possible applications. Sensing impact is presented in [50] with focus on scope and impact analysis of various types of sensors used for industrial and 
other applications. Precision agriculture and satellite data processing are discussed in [35], which utilizes the remotely sensed LiDAR data and helps in smart agriculture applications.

Table 2. Smart Sensors for Remote sensing applications.

\begin{tabular}{ccc}
\hline Research & Method Used & Contributions and Limitations \\
\hline $\begin{array}{c}\text { Understanding smart } \\
\text { sensors }[48,49]\end{array}$ & $\begin{array}{c}\text { Theory and fundamentals of } \\
\text { smart sensors }\end{array}$ & $\begin{array}{c}\text { Smart sensors for a wide range of applications are } \\
\text { covered in the studies with their potential use for a } \\
\text { variety of real time uses including agriculture and } \\
\text { remote sensing applications. }\end{array}$ \\
\hline $\begin{array}{c}\text { Remote monitoring and its } \\
\text { impact [50] }\end{array}$ & $\begin{array}{c}\text { Development actors for } \\
\text { sensing impacts }\end{array}$ & $\begin{array}{c}\text { Sensing impacts of sensors, marketability and } \\
\text { scope are discussed. This scope of the sensing } \\
\text { application is very limited in this contribution. }\end{array}$ \\
$\begin{array}{c}\text { Remote Sensing and precision } \\
\text { agriculture [35] }\end{array}$ & $\begin{array}{c}\text { Satellite data processing and } \\
\text { precision agriculture }\end{array}$ & $\begin{array}{c}\text { LiDAR-based remotely sensed data are used for } \\
\text { precision agriculture applications covering the soil } \\
\text { quality estimation, crops selectivity and enhanced } \\
\text { productivity. More focus is on agriculture } \\
\text { applications and the less emphasis is on remote } \\
\text { sensing aspect. }\end{array}$ \\
\hline
\end{tabular}

\section{IoT for Remote Sensing Applications}

As already underlined in previous sections, IoT finds a wide usage in data acquisition, processing and interpretation in many fields of interest, and Remote Sensing is one of them, being an important area of signal processing research and studies. The smart sensors are in fact used in a wide number of applications related to environmental monitoring such as for instance air quality control; water contamination assessment; water contamination monitoring; radiation assessment, that also contribute to monitoring the territory, the environment and may impact on several fields as listed below. IoT for Remote Sensing Applications is another exciting area of interest where IoT empowers smart systems to detect, sense and analyze various parameters that assist in a robust monitoring of the environment. Figure 2 shows a typical diagram of the scenario in which IoT is used in a number of applications related to Remote Sensing. Some of them are listed as following:

- $\quad$ Forest monitoring and assessment of factors related to plants and animals $[13,37,39]$.

- Agriculture monitoring and assessment of soil quality, water quantity $[1,9,20-22,25,27,28,43,51-53]$.

- Industrial monitoring [20,33].

- $\quad$ Data monitoring $[2,21,29,37,47,51]$.

- $\quad$ Security and surveillance applications $[3,31,46,54]$.

The applications employing smart sensors and dealing with the environment monitoring are described based on the evaluation of various factors, as discussed ahead. As shown in the Figure 2, the role of IoT in Remote Sensing implies the employment of a shared cloud space where a number of sensing, processing and signal transmission components are connected together and share information on parameters and areas of interest.

A number of research papers and articles on IoT for Remote Sensing applications have been analyzed, by summarizing their findings, limitations and their potential impact in Table 3. As highlighted in the table, geospatial analysis, environmental informatics and IoT are used in [55], for analysis of environmental research data which can be utilized for remote sensing and the interpretation for various uses such as weather forecasting, soil and moisture evaluation, etc. is given. In [54], a time series method is applied over Sentinel-1 SAR data, useful for management and classification of various types of crops. This work appears to be helpful both for remote sensing and agriculture applications. A statistical analysis used for agriculture applications using Remote Sensing data is presented in [56], as a handbook issued by United Nations (UN) food and agriculture organizations. A Remote Sensing communication model is presented in [39] showing how a time-sensitive wild fire detection is achieved through Remote Sensing data. In [52], hyper spectral imaging 
is used in agriculture applications, and data classification is performed with the help of a number of regression techniques. In other publications, Remote Sensing utilizing IoT has been discussed, such as precision agriculture using Remote Sensing [1,21,27]; vulnerability analysis [33]; Remote Sensing in agriculture using IoT and sensors [1,21,35,57]; and inland water quality assessment [38].

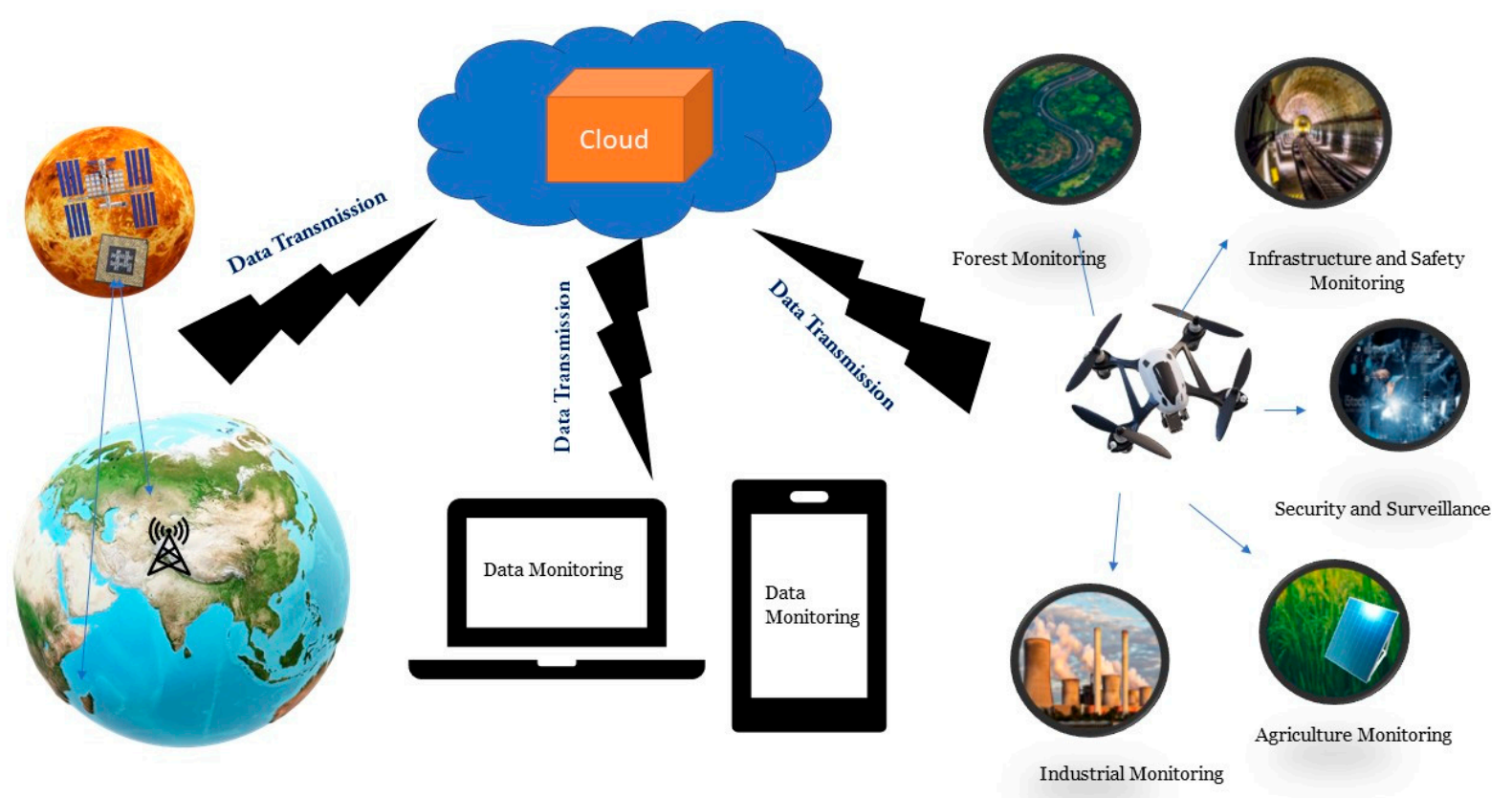

Figure 2. Highlights of the role of IoT in remote sensing applications.

Table 3. IoT for Remote sensing applications.

Research

Geospatial Analysis and IoT [55]

Geospatial Analysis, IoT and Environment informatics are used.

Crop classification [54]
Time series analysis, crop classification. technology [52]

Agricultural statistics analysis [56]

Remote Sensing communication [39]

Hyperspectral imaging in classification.
Remote Sensing communication model are used for wildfire detection.

Hyperspectral imaging techniques are used for agriculture applications. Regression techniques are used

Contributions and Limitations

Environmental Informatics obtained through IoT and the spatial analysis of geospatial techniques help in the interpretation of remotely sensed data. Useful for general purpose environmental research, the analysis however is useful in Remote Sensing applications.

Sentinel-1 data is used for crop classification and management using time series method and SAR

(Synthetic Aperture Radar) data. Classification performance is evaluated in terms of F-1 score and other metrics.

However, the method cannot be generalized for all different crops from any region.

The report presents a complete agricultural statistical analysis using Remote Sensing data.

The model presented helps in detection and avoidance of wildfire and associated hazards. The modeling is not used for dynamic hazardous cases.

UVA-based, satellite-based and airplane-based hyperspectral image analysis is used for agriculture applications. 


\section{Smart Sensors and IoT for Agriculture Applications}

Modern agriculture employing advanced technologies such as AI and smart sensors, can produce increased yields with appropriate crop quality assessment $[16,24,25,54,58]$, crop classification and soil moisture measurement $[20,21,25,43,51,52,59]$. In Figure 3, we can see that smart sensors $[3,6,8,16,26,28,48,60-62]$ are used in the agriculture sector by including modern sensors, advanced AI techniques $[26,27,60]$, soil health monitoring systems, animal-husbandry [63] applications, crop yield [16,23,25,27,51] analysis. The role of smart sensors is extremely important in agriculture and pharma sectors where not only the productivity is enhanced but the sustainable growth is also achieved. The smart sensors and IoT change the conventional agriculture practices into smart farming that helps in empowering the farmers all across the world.

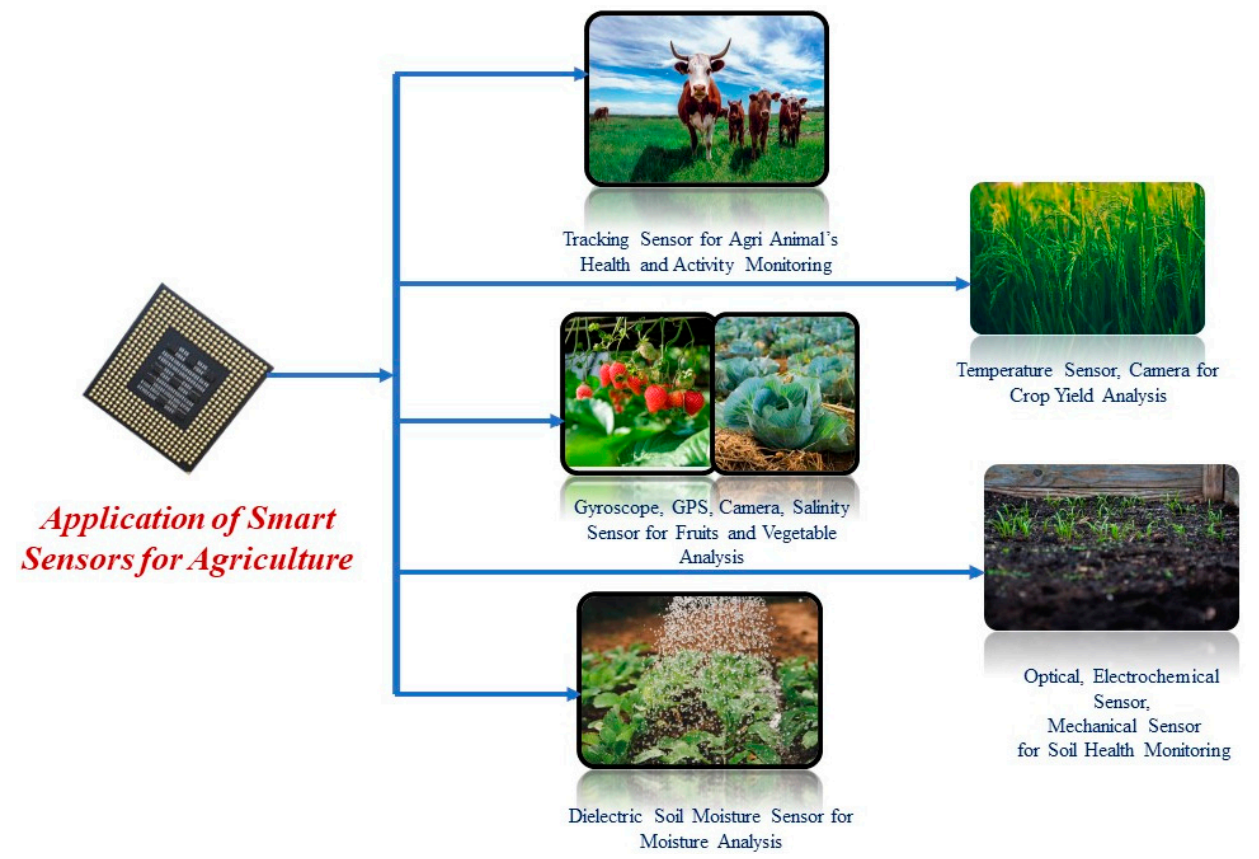

Figure 3. Smart sensors for agriculture applications.

In Figure 4, the IoT which is used in the agriculture sector is highlighted with the help of typical applications such as crop disease [24,27] diagnosis, soil fertility analysis [25], erosion analysis, pesticide and fertilizer control [25-27], crop quality assessment, optical irrigation $[16,23,27,51,64]$, seed quality [1] and smart IoT-based alarm systems for the control of the agriculture production at various stages.

Figure 4 shows the usages of IoT in agricultures, with possible domains of agricultural applications highlighted in a foreground scheme. The research work in the area of IoT and smart sensors used for agricultural applications is depicted in Table 4, where other references are introduced and analyzed. In [57] Big Data and Remote Sensing data are managed and processed for precision agriculture. In [58], cropland agriculture is implemented and crop classification achieved, by showing how the precision agriculture utilizing remote sensed data enhances crop management. However, the work focusses on near-real time implementations, and it can be extended for actual real time usage of the precision agriculture. This is further discussed and explained in [1] using latest sensors for farm management and post-harvest applications. Infrared thermography methods are used for data sensing and the sensors are used for capturing the cultivation data. However, the robust and wide range of sensors can be used to further augmenting the performance in digital and precision agriculture. In another work on precision and smart agriculture [20], smart soil moisture sensors and IoT are used but the long term stability and wood substrate in the soil are major issues as discussed in the paper. Deep learning is used in [46] for multisensory data analysis used in security and surveillance applications. In [22], rural agriculture is 
explained making an effective use of sensors, IoT, ZigBee and Arduino. A number of environmental parameters such as temperature, moisture and soil quality are estimated for guiding the farmers about suitability of crop type and other associated factors, and this can be extended for larger areas. Sensor and IoT-based smart farming is discussed in [22], employing temperature, humidity and moisture sensors. The sensory data are interpreted with the help of IoT which assists in better monitored and planned agriculture yields.

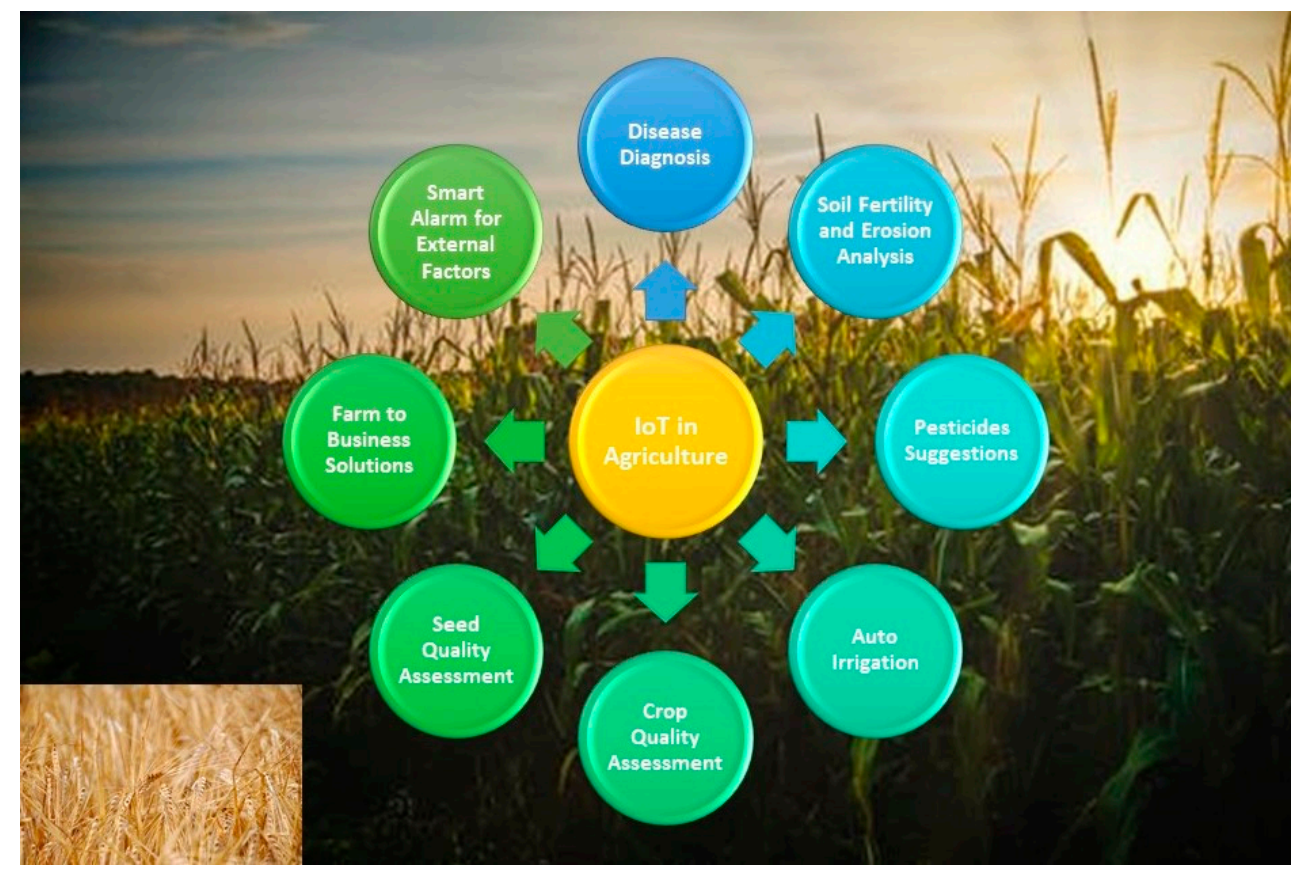

Figure 4. IoT for agriculture applications. A corn crop has been chosen as a background to create a scenic view and in the small box the picture of a ripe and healthy crop ready for harvest is shown as an example.

Table 4. IoT and smart sensors for agriculture applications.

\begin{tabular}{ccc}
\hline Research & Method Used & Contributions and Limitations \\
\hline $\begin{array}{c}\text { Agriculture data } \\
\text { management [57] }\end{array}$ & $\begin{array}{c}\text { Big data, remote sensing and } \\
\text { precision agriculture }\end{array}$ & $\begin{array}{c}\text { This gives analysis of agricultural data captured through } \\
\text { Remote Sensing techniques and IoT, which are simplified } \\
\text { using the Big Data concept. The work is applied for } \\
\text { precision agriculture. However, specific sensors or IoT are } \\
\text { not suggested in the work. }\end{array}$ \\
Cropland agriculture [58] & $\begin{array}{c}\text { Crop classification and } \\
\text { precision agriculture }\end{array}$ & $\begin{array}{c}\text { Non-conventional agriculture with improved productivity } \\
\text { is implemented as precision agriculture method for crop } \\
\text { management and crop classification. This work suggests } \\
\text { that the real time monitoring of crops needs to be achieved } \\
\text { for larger regions. }\end{array}$ \\
\hline Sensors in agriculture [1] & $\begin{array}{c}\text { Infrared thermography methods, } \\
\text { agriculture sensors and } \\
\text { digital farming }\end{array}$ & $\begin{array}{c}\text { Precision agriculture is used for farm management, soil } \\
\text { sensing and post-harvest uses. Wide range of temperature } \\
\text { and humidity sensors can also be used for better sensing. }\end{array}$ \\
\hline $\begin{array}{c}\text { Soil moisture sensors and } \\
\text { IoT [20] }\end{array}$ & Printed disposable sensors and IoT & $\begin{array}{c}\text { Soil moisture is measured using the sensors and IoT that } \\
\text { assist in precision agriculture. Sensing characteristics are } \\
\text { estimated for appropriate farming. Long term stability is a } \\
\text { major concern in the work. }\end{array}$ \\
\hline
\end{tabular}


Table 4. Cont.

\begin{tabular}{ccc}
\hline Research & Method Used & Contributions and Limitations \\
\hline $\begin{array}{c}\text { Multisensory data and } \\
\text { analysis [46] }\end{array}$ & $\begin{array}{c}\text { Deep learning for counter } \\
\text { UAV applications }\end{array}$ & $\begin{array}{c}\text { Multisensory data are interpreted using deep learning for } \\
\text { security and surveillance applications useful for agriculture } \\
\text { uses. Sensor models and classification techniques are } \\
\text { employed for better security and surveillance. The } \\
\text { framework of sensors and classifiers is used rather than a } \\
\text { robust or general purpose method. }\end{array}$ \\
$\begin{array}{c}\text { Sensor network for rural } \\
\text { agriculture [22] }\end{array}$ & $\begin{array}{c}\text { Wireless sensor network, IoT, ZigBee } \\
\text { and Arduino }\end{array}$ & $\begin{array}{c}\text { Rural agricultural environment was created with the help of } \\
\text { wireless sensor network for creating an effective rural } \\
\text { agriculture. The scope of the work needs to be extended for } \\
\text { larger areas since the rural economy is mainly based } \\
\text { on agriculture. }\end{array}$ \\
\hline Smart farming [25] & Sensors and IoT & $\begin{array}{c}\text { Optimal monitoring of farming conditions and smart } \\
\text { agriculture are discussed operating over IoT and sensors. } \\
\text { Soil moisture, temperature and humidity are monitored for } \\
\text { better and smart farming. This prototype needs to be } \\
\text { extended for wide areas' deployment. }\end{array}$ \\
\hline
\end{tabular}

Based on Remote Sensing data and other agricultural data collected with the help of sensors, low cost platforms have been developed for smart farming system with controlled and monitored environmental factors. This type of development requires IoT and UAVs (unmanned aerial vehicles) which operate on the low to middle cost platforms [65-68]. Thus, the agriculture can be improved by making it smart with the help of cutting edge technologies that include Arduino based controls; machine learning and deep learning based approaches, as reported in [69-74]. As a novel platform developed for smart agriculture, it is worth to mention the Flying IoT, which has been tested in real time scenario and its performance has also been evaluated in the context of smart farming carried out in different countries. Crop quality assessment, drought management, losses due to drought are assessed using the low-cost platforms based on IoT. The ground water irrigation monitoring and the definition of its appropriate amount, for instance, are an example of important factors, aimed at improving the crop control, used in implementing remote sensing techniques in smart farming. There are in fact some indices used in smart agriculture which can benefit the employment of using the IoT and the sensor networks. A few major indices are as follows:

- $\quad$ Evaporative stress index (ESI).

- Vegetation health index (VHI).

- Enhanced vegetation index (EVI).

- $\quad$ Standardized anomaly index (SAI).

The above indices or metrics are computed utilizing satellite-based Remote Sensing data. To give an idea of their importance, it is worth to highlight how the value of ESI is expected to be always good since an indication of the agricultural drought. The VHI indicates the health of vegetation and EVI shows the improvement in the VHI. Calculation of SAI is based on the other indices.

\section{Discussion of the Review}

The methodology for completing this work includes critical review of most important research in the field of IoT and smart sensors used for Remote Sensing and agriculture, also because smart agriculture depends on remotely sensed data and forecasting to a considerable extent. The review is followed by a comparison of different types of smart sensors and IoT used, based on types of sensors employed, methodology adopted, application and challenges. Based on the study and review of the selected research works in the area of IoT and smart sensors used for Remote Sensing and agriculture applications, the following challenges are seen as major shortcomings of the existing literature, as follows: 
- No specific method has been suggested as robust method for smart agriculture. This means that a specific type of smart sensor is not recommended for numerous applications. In fact, a set of sensors and different IoT-based devices are generally used invariable in the applications. Thus, a framework of smart sensors needs to be highlighted for agriculture and Remote Sensing applications, in particular.

- Wide range of sensors and IoT devices are used in different pieces of research which poses a major challenge on choosing appropriate sensors for a particular application.

- Statistical analysis and modelling for assessment of performance are missing in most of the researches.

- The interoperability issues of sensors and their deployment are also important limitations.

- The amount of research in the specific areas of IoT and sensors for Remote Sensing applications is very limited. So, the research efforts in these sectors needs to be strengthened.

- The applications highlighted in various existing literature cover diverse areas of usage of smart sensors that again pose challenges related to robust practices or approaches. This means that the methods used while implementing the sensors are not specific in various studies already made in the literature. This observation is based on the exploration of various types of literature reported by important databases (shown in Tables 5 and 6). The research suggests that sensors employed are not robust due to the fact that environmental condition, image noise, artefacts and many other factors are invariably considered in most of the articles, and similarly are the sensors required as per the necessity, namely for addressing the issues involved in the applications. As regards the research on smart sensors and IoT specifically for remote sensing and agriculture applications, this is very limited and thus it has been very difficult to bring out a substantial conclusion here about robustness. This is why a framework of sensors for covering most of the scopes of remote sensing is recommended, that may include a set of sensors as well as the common types of sensor networks viable for such applications in smart agriculture. The suggested framework may be useful because the number of environment factors and other issues involved in these applications can be broadly classified and the specific sensor requirements can be categorized for further extension of their employment.

- Selection of environmental parameters that affect agriculture sector needs to be judiciously made and for this, robust set of parameters can be investigated.

- The smart sensors especially for monitoring the parameters involved in weather forecasting for farmers should be appropriately chosen for the specific application.

- The design of IoT has been a less touched are in the field of IoT and smart sensors and thus specific design methods need to be researched more.

Table 5. Research contributions and their impact (Science Direct Database).

\begin{tabular}{cccccc}
\hline \multirow{2}{*}{ Research } & \multicolumn{5}{c}{ Number of Research Contributions } \\
\cline { 2 - 6 } & $\mathbf{2 0 1 7}$ & $\mathbf{2 0 1 8}$ & $\mathbf{2 0 1 9}$ & $\mathbf{2 0 2 0}$ & 2021 (Till Date) \\
\hline $\begin{array}{c}\text { IoT for remote sensing } \\
\text { applications }\end{array}$ & 424 & 627 & 941 & 1334 & 913 \\
\hline $\begin{array}{c}\text { Smart sensors for remote } \\
\text { sensing applications }\end{array}$ & 1289 & 1505 & 2028 & 1316 & 1 \\
\hline $\begin{array}{c}\text { Smart sensors and IoT for } \\
\text { agriculture applications } \\
\text { Smart remote sensing systems }\end{array}$ & 142 & 215 & 407 & 679 & 449 \\
\hline
\end{tabular}


Table 6. Research contributions and their impact (Google Scholar-MDPI, IEEE and ACM Databases).

\begin{tabular}{cccc}
\hline & \multicolumn{3}{c}{ Number of Research Contributions } \\
\cline { 2 - 4 } Research & $\begin{array}{c}\text { Google Scholars } \\
\text { Including MDPI } \\
\mathbf{( 2 0 1 7 - 2 0 2 1 )}\end{array}$ & $\begin{array}{c}\text { IEEE } \\
\mathbf{( 2 0 1 7 - 2 0 2 1 )}\end{array}$ & $\begin{array}{c}\text { ACM } \\
\text { (Last 5 years) }\end{array}$ \\
\hline $\begin{array}{c}\text { IoT for remote sensing applications } \\
\text { Smart sensors for remote } \\
\quad \text { sensing applications }\end{array}$ & 17,000 & 252 & 153,182 \\
$\begin{array}{c}\text { Smart sensors and IoT for } \\
\text { agriculture applications }\end{array}$ & 16,400 & 226 & 153,554 \\
Smart remote sensing systems & 17,100 & 319 & 153,553 \\
\hline
\end{tabular}

In Table 5, we have shown the number of research publications of various works in the field of IoT and sensors for Remote Sensing applications. The data are taken from Science Direct source of research in the field of IoT and smart sensors and it is obvious from the data that the amount of work needs to be increased though a certain increase is reported in recent years. The robust sensors and a framework of IoT are actually required to design IoT-based Remote Sensing applications that can help in environment monitoring, weather forecasting as well as in smart or precision agriculture. As it can be seen in Table 5, the research in the field of smart sensors and IoT used in Remote Sensing and agriculture applications, is gaining momentum. However, much has yet to be carried out on implementation challenges and robustness while deploying the sensors in smart agriculture systems. In addition to IoT and sensors, focus on sensor network is also needed as the network plays significant role in deployment and poses some of its own specific issues. The satellite data and its processing can be of good help in estimating weather conditions and forecast that benefit the farmers to smartly enhance agriculture production. The monitoring of specific parameters of environment such as temperature, humidity, solid moisture level, etc., is equally important and thus all these sensors need to be included in a whole framework for agriculture and Remote Sensing applications.

A clarification at the end of this section is necessary. In this manuscript, the term "smart" has been used several times, namely smart sensors, smart agriculture, smart farming, etc. This is commonly due to the use of powerful soft computing techniques called as AI techniques. The attempt has been made in bringing out the specific applications of smart sensors in the Remote Sensing field along with challenges and types of sensors used. However, the focus on AI technologies and their detail is not in the scope of this study.

We have also explored the research impact in the proposed field in few more important databases, namely Google Scholar-MDPI, IEEE digital library (IEEE Explore) and ACM digital library. The summary of the research contributions in these databases can be seen in Table 6.

It can be seen that the research impact and quantum of contributions in the area of smart sensors and IoT for agriculture as well as remote sensing applications, is very limited in IEEE database. The research articles reported in IEEE Explore are very specific and noteworthy on remote sensing and agriculture applications. However, the methodologies used; the types of sensors; and the various network architectures are not robust in most of the literature reported. On the other hand, the number of articles and their impact are significantly reported in ACM databases, almost 150 thousand or more in each sub-domain of research on the proposed topic. Similarly, Google Scholar reported sufficient number of research articles in the field of smart sensors used for agriculture and remote-sensing-based usages. An attempt has been made in exploring the contributions separately in MDPI databases, but the keywords used in Table 6 did not result into any literature. However, Google Scholar database literature includes MDPI articles also. An important observation is that the literature reported by Google Scholar and ACM digital library is not focused and includes several inter-related works on remote sensing and agriculture applications, such as image enhancement, image restoration and segmentation. In addition, more focus 
was given to the image processing part of the research, rather than on role of sensors and IoT. Therefore, this again infers that a robust framework of IoT and smart sensors needs to be developed for viable applications in remote sensing and smart agriculture.

\section{Conclusions}

This paper critically reviews the current status of research and studies in the field of IoT and sensors used for Remote Sensing applications and also in precision agriculture. The literature and a critical review of the work in different fields of smart sensors and IoT in terms of their use, characteristics and limitations have been extensively studied and presented. The recommendations and discussion based on the review have been made in addition to the impact analysis of amount of research carried out in recent years in the area of study. A requirement of framework of IoT and robust set of sensors is recommended for efficient Remote Sensing applications and their deployment. Despite the fact that there are a huge number of sensors for various applications, the sensors for Remote Sensing that result in a novel and robust remote sensing based agriculture monitoring and control is quite limited. Moreover, the statistics and their use in various literature are rarely used in the research and thus future work can attempt the statistical analysis and performance evaluation of IoT and sensors for the cited applications. Specific work on robustness, selection of sensors, environmental parameters, design of suitable IoT and smart sensors, needs to be carried out in the future.

Author Contributions: All authors contributed equally to the work. All authors have read and agreed to the published version of the manuscript.

Funding: This research received no external funding.

Conflicts of Interest: The authors declare no conflict of interest.

\section{References}

1. Kayad, A.; Paraforos, D.; Marinello, F.; Fountas, S. Latest advances in sensor applications in agriculture. Agriculture 2020, 10, 362. [CrossRef]

2. Koo, D.D.; Lee, J.J.; Sebastiani, A.; Kim, J. An Internet-of-Things (IoT) system development and implementation for bathroom safety enhancement. Procedia Eng. 2016, 145, 396-403. [CrossRef]

3. Elahi, H.; Munir, K.; Eugeni, M.; Atek, S.; Gaudenzi, P. Energy harvesting towards self-powered IoT devices. Energies 2020, 13, 5528. [CrossRef]

4. An, B.W.; Shin, J.H.; Kim, S.-Y.; Kim, J.; Ji, S.; Park, J.; Lee, Y.; Jang, J.; Park, Y.-G.; Cho, E.; et al. Smart sensor systems for wearable electronic devices. Polymers 2017, 9, 303. [CrossRef] [PubMed]

5. Cordelli, E.; Pennazza, G.; Sabatini, M.; Santonico, M.; Vollero, L. An open-source smart sensor architecture for edge computing in IoT applications. Proceedings 2018, 2, 955. [CrossRef]

6. Hassan, R.; Qamar, F.; Hasan, M.K.; Aman, A.H.M.; Ahmed, A.S. Internet of Things and its applications: A comprehensive survey. Symmetry 2020, 12, 1674. [CrossRef]

7. Li, S.; Simonian, A.; Chin, B.A. Sensors for agriculture and the food industry. Electrochem. Soc. Interface 2010, 19, 41-46. [CrossRef]

8. Sinha, G.R. Advances in Modern Sensors_Physics, Design, Simulation and Applications; IOP Publishing: Bristol, UK, 2020.

9. Ullo, S.L.; Sinha, G.R. Advances in smart environment monitoring systems using IoT and sensors. Sensors 2020, $20,3113$. [CrossRef]

10. Carminati, M.; Sinha, G.R.; Mohdiwale, S.; Ullo, S.L. Miniaturized pervasive sensors for indoor health monitoring in smart cities. Smart Cities 2021, 4, 146-155. [CrossRef]

11. Ullo, S.L.; Zarro, C.; Wojtowicz, K.; Meoli, G.; Focareta, M. LiDAR-based system and optical VHR data for building detection and mapping. Sensors 2020, 20, 1285. [CrossRef]

12. Ullo, S.L.; Addabbo, P.; Di Martire, D.; Sica, S.; Fiscante, N.; Cicala, L.; Angelino, C.V. Application of DInSAR technique to high coherence Sentinel-1 images for dam monitoring and result validation through in situ measurements. IEEE J. Sel. Top. Appl. Earth Obs. Remote. Sens. 2019, 12, 875-890. [CrossRef]

13. Addabbo, P.; Focareta, M.; Marcuccio, S.; Votto, C.; Ullo, S.L. Contribution of Sentinel-2 data for applications in vegetation monitoring. Acta IMEKO 2016, 5, 44-54. [CrossRef]

14. Addabbo, P.; Angrisano, A.; Bernardi, M.L.; Gagliarde, G.; Mennella, A.; Nisi, M.; Ullo, S.L. UAV system for photovoltaic plant inspection. IEEE Aerosp. Electron. Syst. Mag. 2018, 33, 58-67. [CrossRef] 
15. Vasisht, D.; Kapetanovic, Z.; Won, J.; Jin, X.; Chandra, R.; Kapoor, A.; Sinha, S.N.; Sudarshan, M.; Stratman, S. Farmbeats: An IoT platform for data-driven agriculture. In Proceedings of the 14th USENIX Symposium on Networked Systems Design and Implementation (NSDI '17), Boston, MA, USA, 27-29 March 2017; pp. 515-529.

16. Ayaz, M.; Ammad-Uddin, M.; Sharif, Z.; Mansour, A.; Aggoune, E.-H.M. Internet-of-Things (IoT)-based smart agriculture: Toward making the fields talk. IEEE Access 2019, 7, 129551-129583. [CrossRef]

17. Ji, C.; Lu, H.; Ji, C.; Yan, J. An IoT and mobile cloud-based architecture for smart planting. In Proceedings of the 2015 3rd International Conference on Machinery, Materials and Information Technology Applications, Qingdao, China, 28-29 November 2015; pp. 1001-1005.

18. Arridha, R.; Sukaridhoto, S.; Pramadihanto, D.; Funabiki, N. Classification extension based on IoT-big data analytic for smart environment monitoring and analytic in real-time system. Int. J. Space-Based Situat. Comput. 2017, 7, 82-93. [CrossRef]

19. Tawalbeh, L.; Muheidat, F.; Tawalbeh, M.; Quwaider, M. IoT privacy and security: Challenges and solutions. Appl. Sci. 2020, 10, 4102. [CrossRef]

20. Syrový, T.; Vik, R.; Pretl, S.; Syrová, L.; Čengery, J.; Hamáček, A.; Kubáč, L.; Menšík, L. Fully printed disposable IoT soil moisture sensors for precision agriculture. Chemosensors 2020, 8, 125. [CrossRef]

21. Shafi, U.; Mumtaz, R.; García-Nieto, J.; Hassan, S.A.; Zaidi, S.A.R.; Iqbal, N. Precision agriculture techniques and practices: From considerations to applications. Sensors 2019, 19, 3796. [CrossRef]

22. Robles, J.R.; Martin, Á.; Martin, S.; Ruipérez-Valiente, J.; Castro, M. Autonomous sensor network for rural agriculture environments, low cost, and energy self-charge. Sustainability 2020, 12, 5913. [CrossRef]

23. Madushanki, A.R.; Halgamuge, M.N.; Wirasagoda, W.S.; Syed, A. Adoption of the Internet of Things (IoT) in agriculture and smart farming towards urban greening: A review. Int. J. Adv. Comput. Sci. Appl. 2019, 10, 11-28. [CrossRef]

24. Marcu, I.; Voicu, C.; Drăgulinescu, A.M.C.; Fratu, O.; Suciu, G.; Balaceanu, C.M.; Andronache, M.M. Overview of IoT basic platforms for precision agriculture. In Lecture Notes of the Institute for Computer Sciences, Social Informatics and Telecommunications Engineering; Springer International Publishing: Berlin/Heidelberg, Germany, 2019; Volume 283, pp. $124-137$.

25. Doshi, J.; Patel, T.; Bharti, S.K. Smart farming using IoT, a solution for optimally monitoring farming conditions. Procedia Comput. Sci. 2019, 160, 746-751. [CrossRef]

26. Aggarwal, N.; Singh, D. Technology assisted farming: Implications of IoT and AI. In Proceedings of the 1st International Conference on Computational Research and Data Analytics (ICCRDA 2020), Rajpura, India, 24 October 2020; IOP Publishing: Bristol, UK, 2021; Volume 1022, p. 012080.

27. Sishodia, R.P.; Ray, R.L.; Singh, S.K. Applications of remote sensing in precision agriculture: A review. Remote. Sens. 2020, $12,3136$. [CrossRef]

28. Lakshmisudha, K.; Hegde, S.; Kale, N.; Iyer, S. Smart precision-based agriculture using sensors. Int. J. Comput. Appl. 2016, 146, 36-38. [CrossRef]

29. Di Napoli, M.; Marsiglia, P.; Di Martire, D.; Ramondini, M.; Ullo, S.; Calcaterra, D. Landslide susceptibility assessment of wildfire burnt areas through Earth-observation techniques and a machine learning-based approach. Remote. Sens. 2020, 12, 2505. [CrossRef]

30. Carminati, M.; Kanoun, O.; Ullo, S.L.; Marcuccio, S. Prospects of distributed wireless sensor networks for urban environmental monitoring. IEEE Aerosp. Electron. Syst. Mag. 2019, 34, 44-52. [CrossRef]

31. Brown, A.; Bethel, G.; Koehler, S. Threats to Precision Agriculture; Public-Private Analytic Exchange Program (AEP): Washington, DC, USA, 2018; p. 25.

32. Jing, L.; Ying, C.; Meishan, J.; Yannan, Z.; Changhong, D. Application of laser remote sensing technology and super continuous spectrum laser. In Proceedings of the 2020 2nd International Conference on Civil Architecture and Energy Science (CAES 2020), Online. 1 May 2020. [CrossRef]

33. Yekeen, S.T.; Balogun, A.-L. Advances in remote sensing technology, machine learning and deep learning for marine oil spill detection, prediction and vulnerability assessment. Remote. Sens. 2020, 12, 3416. [CrossRef]

34. Zhu, L.; Suomalainen, J.; Liu, J.; Hyyppä, J.; Kaartinen, H.; Haggren, H. A review: Remote sensing sensors. Multi Purp. Appl. Geospat. Data 2018. [CrossRef]

35. Khanal, S.; Kc, K.; Fulton, J.P.; Shearer, S.; Ozkan, E. Remote sensing in agriculture-Accomplishments, limitations and opportunities. Remote. Sens. 2020, 12, 3783. [CrossRef]

36. Avtar, R.; Kouser, A.; Kumar, A.; Singh, D.; Misra, P.; Gupta, A.; Yunus, A.; Kumar, P.; Johnson, B.; Dasgupta, R.; et al. Remote sensing for international peace and security: Its role and implications. Remote. Sens. 2021, 13, 439. [CrossRef]

37. Inglada, J.; Arias, M.; Tardy, B.; Hagolle, O.; Valero, S.; Morin, D.; Dedieu, G.; Sepulcre, G.; Bontemps, S.; Defourny, P.; et al. Assessment of an operational system for crop type map production using high temporal and spatial resolution satellite optical imagery. Remote. Sens. 2015, 7, 12356-12379. [CrossRef]

38. Topp, S.N.; Pavelsky, T.M.; Jensen, D.; Simard, M.; Ross, M.R.V. Research trends in the use of remote sensing for inland water quality science: Moving towards multidisciplinary applications. Water 2020, 12, 169. [CrossRef]

39. Lippitt, C.D.; Stow, D.A.; Riggan, P.J. Application of the remote-sensing communication model to a time-sensitive wildfire remote-sensing system. Int. J. Remote. Sens. 2016, 37, 3272-3292. [CrossRef]

40. Brewster, C.; Roussaki, I.; Kalatzis, N.; Doolin, K.; Ellis, K. IoT in agriculture: Designing a Europe-wide large-scale pilot. IEEE Commun. Mag. 2017, 55, 26-33. [CrossRef] 
41. Hadzovic, S.; Mrdovic, S.; Radonjic, M. Identification of IoT actors. Sensors 2021, 21, 2093. [CrossRef] [PubMed]

42. Reeve, H.M.; Mescher, A.M.; Emery, A.F. Experimental and numerical investigation of polymer preform heating. J. Mater. Process. Manuf. Sci. 2001, 9, 285-301. [CrossRef]

43. Fisher, D.K.; Woodruff, L.K.; Anapalli, S.S.; Pinnamaneni, S.R. Open-source wireless cloud-connected agricultural sensor network. J. Sens. Actuator Netw. 2018, 7, 47. [CrossRef]

44. Koulamas, C.; Lazarescu, M.T. Real-time sensor networks and systems for the industrial IoT: What next? Sensors 2020, 20, 5023. [CrossRef]

45. GSMA (Groupe Speciale Mobile Association). Understanding the Internet of Things (IoT). GSMA Connect. Living $2014,15$.

46. Samaras, S.; Diamantidou, E.; Ataloglou, D.; Sakellariou, N.; Vafeiadis, A.; Magoulianitis, V.; Lalas, A.; Dimou, A.; Zarpalas, D.; Votis, K.; et al. Deep learning on multi sensor data for counter UAV applications-A systematic review. Sensors 2019, $19,4837$. [CrossRef]

47. Corradini, S.; Guerrieri, L.; Stelitano, D.; Salerno, G.; Scollo, S.; Merucci, L.; Prestifilippo, M.; Musacchio, M.; Silvestri, M.; Lombardo, V.; et al. Near real-time monitoring of the Christmas 2018 Etna eruption using SEVIRI and products validation. Remote Sens. 2020, 12, 1336. [CrossRef]

48. Abbott, P. Understanding Smart Sensors; Artech House: London, UK, 1998; Volume 18, ISBN 0890063117.

49. Randy, R.F.; Frank, F. Understanding Smart Sensors, 3rd ed.; Artech House: London, UK, 2013.

50. Dive, G.D. Sensing Impacts: Remote Monitoring Using Sensors; Innovation for Poverty Action (IPA): New Haven, CT, USA, 2016; pp. 1-20.

51. Lakhankar, T.; Krakauer, N.; Khanbilvardi, R. Applications of microwave remote sensing of soil moisture for agricultural applications. Int. J. Terraspace Sci. Eng. 2009, 2, 81-91.

52. Lu, B.; Dao, P.; Liu, J.; He, Y.; Shang, J. Recent advances of hyperspectral imaging technology and applications in agriculture. Remote. Sens. 2020, 12, 2659. [CrossRef]

53. Daponte, P.; De Vito, L.; Glielmo, L.; Iannelli, L.; Liuzza, D.; Picariello, F.; Silano, G. A review on the use of drones for precision agriculture. In Proceedings of the 1st Workshop on Metrology for Agriculture and Forestry (METROAGRIFOR), Ancona, Italy, 1-2 October 2018; p. 012022. [CrossRef]

54. Arias, M.; Campo-Bescós, M.Á.; Álvarez-Mozos, J. Crop classification based on temporal signatures of Sentinel-1 observations over Navarre province, Spain. Remote. Sens. 2020, 12, 278. [CrossRef]

55. Kamilaris, A.; Ostermann, F. Geospatial analysis and Internet of Things in environmental informatics. arXiv 2018, arXiv:1808.01895.

56. Davidson, A.M.; Fisette, T.; McNairn, H.; Daneshfar, B. Chapter 4-Detailed crop mapping using remote sensing data (crop data layers). In Handbook on Remote Sensing for Agricultural Statistics; Delincé, J., Ed.; Food and Agriculture Organization of the United Nations: Rome, Italy, 2014.

57. Huang, Y.; Chen, Z.-X.; Yu, T.; Huang, X.-Z.; Gu, X.-F. Agricultural remote sensing big data: Management and applications. J. Integr. Agric. 2018, 17, 1915-1931. [CrossRef]

58. Nellis, M.D.; Price, K.P.; Rundquist, D. Remote Sensing of Cropland Agriculture; SAGE Publications: Thousand Oaks, CA, USA, 2013; pp. 368-382.

59. Piikki, K.; Söderström, M.; Eriksson, J.; John, J.M.; Muthee, P.I.; Wetterlind, J.; Lund, E. Performance evaluation of proximal sensors for soil assessment in smallholder farms in Embu County, Kenya. Sensors 2016, 16, 1950. [CrossRef]

60. Zhang, D.; Wei, B. Smart sensors and devices in artificial intelligence. Sensors 2020, 20, 5945. [CrossRef] [PubMed]

61. Kalsoom, T.; Ramzan, N.; Ahmed, S.; Ur-Rehman, M. Advances in sensor technologies in the era of smart factory and industry 4.0. Sensors 2020, 20,6783. [CrossRef]

62. Suanpang, P.; Jamjuntr, P. A smart farm prototype with an Internet of Things (IoT) case study: Thailand. J. Adv. Agric. Technol. 2019, 6, 241-245. [CrossRef]

63. Safety, F. Smart Farming and Food Safety Internet of Things Applications-Challenges for Large Scale Implementations; Alliance for Internet of Things Innovation (AIOTI): Brussels, Belgium, 2015.

64. Patel, B.C.; Sinha, G.R.; Goel, N. Introduction to sensors. In Advances in Modern Sensors; Sinha, G.R., Ed.; IOP Publishing: Bristol, UK, 2020; pp. 2-6.

65. Almalki, F.; Soufiene, B.; Alsamhi, S.; Sakli, H. A low-cost platform for environmental smart farming monitoring system based on IoT and UAVs. Sustainability 2021, 13, 5908. [CrossRef]

66. Sharma, G.; Shrestha, S.; Kunwar, S.; Tseng, T.-M. Crop diversification for improved weed management: A review. Agriculture 2021, 11, 461. [CrossRef]

67. Shahzaman, M.; Zhu, W.; Bilal, M.; Habtemicheal, B.; Mustafa, F.; Arshad, M.; Ullah, I.; Ishfaq, S.; Iqbal, R. Remote sensing indices for spatial monitoring of agricultural drought in South Asian countries. Remote. Sens. 2021, 13, 2059. [CrossRef]

68. Sarwar, A.; Ahmad, S.; Rehmani, M.; Javid, M.A.; Gulzar, S.; Shehzad, M.; Dar, J.S.; Baazeem, A.; Iqbal, M.; Rahman, M.; et al. Mapping groundwater potential for irrigation, by geographical information system and remote sensing techniques: A case study of district Lower Dir, Pakistan. Atmosphere 2021, 12, 669. [CrossRef]

69. Shafi, U.; Mumtaz, R.; Iqbal, N.; Zaidi, S.M.H.; Hussain, I.; Mahmood, Z. A Multi-modal approach for crop health mapping using low altitude remote sensing, Internet of Things (IoT) and machine learning. IEEE Access 2020, 8, 112708-112724. [CrossRef] 
70. Ruan, J.; Jiang, H.; Zhu, C.; Hu, X.; Shi, Y.; Liu, T.; Rao, W.; Chan, F.T. Agriculture IoT: Emerging trends, cooperation networks, and outlook. IEEE Wirel. Commun. 2019, 26, 56-63. [CrossRef]

71. Vargas, J.Q.; Khot, L.R.; Peters, R.T.; Chandel, A.K.; Molaei, B. Low orbiting satellite and small UAS-based high-resolution imagery data to quantify crop lodging: A case study in irrigated spearmint. IEEE Geosci. Remote. Sens. Lett. 2020, 17, 755-759. [CrossRef]

72. Saha, R.; Chakraborty, A.; Misra, S.; Das, S.K.; Chatterjee, C. DLSense: Distributed learning-based smart virtual sensing for precision agriculture. IEEE Sensors J. 2021, 1. [CrossRef]

73. Sushanth, G.; Sujatha, S. IoT based smart agriculture system. In Proceedings of the 2018 International Conference on Wireless Communications, Signal Processing and Networking (WiSPNET), Chennai, India, 22-24 March 2018; pp. 1-4.

74. Kashyap, B.; Kumar, R. Sensing methodologies in agriculture for soil moisture and nutrient monitoring. IEEE Access 2021, 9, 14095-14121. [CrossRef] 